\title{
Factors Associated with Untreated Decayed Teeth in Male Sales Workers: An Internet Survey
}

\author{
Yoichi Ishizuka $^{1)}$, Koichi Yoshino ${ }^{1)}$, Seitaro Suzuki ${ }^{1)}$, Ryouichi Sato ${ }^{1)}$, \\ Yuki Onose $^{1)}$, Takako Eguchi ${ }^{1,2)}$, Atsushi Takayanagi ${ }^{1)}$, Hideyuki Kamijo ${ }^{3)}$ \\ and Naoki Sugihara ${ }^{1)}$ \\ ${ }^{1)}$ Department of Epidemiology and Public Health, Tokyo Dental College, \\ 2-9-18 Kanda-Misakicho, Chiyoda-ku, Tokyo 101-0061, Japan \\ ${ }^{2)}$ Department of Dental Hygiene, Tokyo Dental Junior College, \\ 2-9-18 Kanda-Misakicho, Chiyoda-ku, Tokyo 101-0061, Japan \\ ${ }^{3)}$ Department of Social Security for Dentistry, Tokyo Dental College, \\ 2-9-18 Kanda-Misakicho, Chiyoda-ku, Tokyo 101-0061, Japan
}

Received 11 September, 2018/Accepted for Publication 17 October, 2018 Published Online in J-STAGE 16 July, 2019

\begin{abstract}
The purpose of this study was to identify factors associated with untreated decayed teeth (DT) in male sales workers. The participants were recruited by screening a pool of Japanese registrants in an online database for eligibility for inclusion in the study. Between 20 February 2015 and 11 March 2015, those deemed eligible were asked to complete a questionnaire on the status of their oral health. Responses from a total of 142 male sales workers aged between 30 and 49 years were analyzed. Of these, 40 reported DT and 102 no untreated decayed teeth (NDT). The percentage of participants with DT was higher than that with NDT among night shift workers $(p<0.001)$. A higher percentage of participants with DT reported pain when eating or drinking something cold $(p=0.041)$, pain in the teeth or gingiva $(p<0.001)$, or frequent stomatitis $(p=0.030)$. A higher percentage of participants with DT reported eating between meals $(p=0.027)$ and a lower percentage visiting a dental clinic in the past 6 months $(p=0.017)$ compared with among participants with NDT. Those with NDT were more likely to report an inability to visit a dental clinic when they wanted to $(p=0.033)$, but those with DT were more likely to report that their reasons for not visiting a dental clinic were that multiple visits were required for treatment $(\mathrm{p}=0.012)$ or that they did not like the treatment $(\mathrm{p}=0.005)$. Working the night shift (Odds Ratio [OR], 3.492; 95\% Confidence Interval [CI], 1.347$8.725)$ and visiting a dental clinic in the past 6 months (OR, 0.084; 95\%CI, $0.010-0.733$ ) were identified as independent variables correlated with leaving DT untreated. Requiring oral health education and dental checkups at least once every 6 months may have a positive effect on oral health among male sales workers, especially those doing night shifts.
\end{abstract}

Key words: Occupational oral health - Sales workers - Untreated decayed teeth Oral health behavior — Night shift work 


\section{Introduction}

Work-related diseases are multifactorial, with the work environment playing a partial role in causation. Such diseases include chronic non-communicable diseases affecting working populations ${ }^{7}$. They also include musculoskeletal disorders ${ }^{24)}$, stress and mental health disorders ${ }^{29)}$, work-related cancer ${ }^{14)}$, skin diseases ${ }^{3)}$, and work-related diseases arising from exposure to biological agents ${ }^{19}$. Various studies have reported an association between job type and particular diseases, with professional drivers being reported to be at risk for diseases such as cardiovascular disease, diabetes mellitus, and lower back pain, for example ${ }^{16,18)}$. Again, other studies have reported an association between sales work and testicular cancer ${ }^{32)}$ or lingual dystonia ${ }^{33)}$ due to the working environment characteristic of this occupation.

An association between job type and oral conditions has also been reported. Some studies have suggested that oral health status may be associated with job classification in $\operatorname{Japan}^{10,11,20,21,35)}$. Only a few studies have investigated associations between oral conditions and job type, however. One study found that professional drivers had fewer teeth than white-collar workers ${ }^{311}$.

Caries and periodontitis are the most common causes of loss of permanent teeth globally, and Japan is no exception in this respect $^{1,22,34)}$. Caries and its sequelae $(43.3 \%$ combined) and periodontal disease (41.8\%) were reported to be the main reasons for tooth extraction in Japan, and extraction due to caries or root fracture were commonly observed in all age groups over 15 years of age $^{1)}$. Furthermore, the incidence of vertical root fracture, which is mainly caused by endodontic treatment, is increasing ${ }^{34)}$. Taken together, this indicates the importance of workers seeking treatment for decayed teeth as soon as possible.

Previous studies by the present group have investigated oral health status and behavior in workers by means of Internet-based surveys $^{12,31)}$. The focus in the present study, how- ever, was on sales workers alone, as oral conditions differ depending on occupation. Our hypothesis was that sales workers who had a bad lifestyle, especially those who ate between meals, would have untreated decayed teeth (DT). The purpose of this study was to reveal factors associated with DT in male sales workers.

\section{Methods}

\section{Selection of participants}

This Internet-based survey was conducted in Japan between 20 February 2015 and 11 March 2015. Participants were selected from a pool of people registered with an online research company called Macromill (https:/ / www.macromill.com/) who had agreed to participate in oral health-related surveys when they registered. These registrants were invited to participate in this survey and provided informed consent by clicking the corresponding button, after which they were screened for eligibility for enrolment. The questionnaire for this study was then sent to those registrants who met the following criteria: age, 30-49 years; sex, male; occupation, sales worker. The registrants then filled out the questionnaire and sent their responses via e-mail.

Data were collected from a total of 182 initially eligible respondents, among whom 40 whose annual family income was more than 10 million yen or unknown were subsequently excluded from the analysis to minimize the effect of income. A total of 142 male sales workers were therefore included in the final analysis. Among these, 40 had DT and 102 no DT (NDT). Respondents who had DT were defined as those who answered having one or more untreated teeth with a cavity or hole in the questionnaire described below. Participants were divided into two age groups: those aged $30-39$ years and those aged $40-49$ years.

\section{Questionnaire items}

Respondents were asked to report the following: annual household income; the num- 
ber of years of service in their job; their work schedule (night shift workers were defined as those working on a shift rotation schedule that included the 10 p.m. through 5 a.m. period); smoking status (current smoker or not); diabetes and hypertension status (yes or no); and height and weight (the body-mass index (BMI) was then calculated and categorized as $<25$ or $\geq 25$ ). Oral health status items comprised the number of present teeth; the presence or absence of at least one untreated tooth with a cavity or hole; and the presence or absence of the following symptoms: pain when eating or drinking something cold, pain in the teeth or gingiva, bleeding from the gingiva, swelling in the gingiva, difficulty opening the mouth, bad breath, and frequent stomatitis. Concerning oral health behavior, respondents were asked whether they brushed their teeth every day or not; how frequently they brushed their teeth every day $(<2$ or $\geq 2)$; whether they brushed before going to bed or not; whether they used fluoride toothpaste or not; how many minutes they spent brushing their teeth $(<3$ or $\geq 3)$; whether they used dental floss or an interdental brush or neither (yes or no); whether they ate between meals or not; whether they had a regular dental clinic or not; whether they had visited a dental clinic within the past 6 months or not; whether they were able to visit a dental clinic when they wanted to or not; and the reasons why they were unable to visit a dental clinic (unable to go during the hours the clinic was open, cost of treatment, too busy, multiple visits required for treatment, and disliking treatment).

\section{Statistical analysis}

A chi-squared test (or Fisher's exact test in cases with fewer than 5 cells in the contingency table) was used to make comparisons between the NDT and DT groups. The MannWhitney $U$ test was used for an inter-group comparison of number of teeth.

Odds ratios (ORs) and 95\% confidence intervals (CIs) were determined using multiple logistic regression analyses (forced entry method). The dependent variable was set as participants with untreated decayed teeth. The model included variables showing a difference in association between NDT and DT. Age, annual household income, eating between meals, night shift, and visiting a dental clinic in the past 6 months were set as the independent variables. The data was analyzed using IBM SPSS Statistics, Version 25.0 (IBM Corp., Armonk, NY, USA). This study was approved by the Ethics Committee of Tokyo Dental College (Approval no: 602).

\section{Results}

Table 1 shows a comparison of the basic characteristics, general health behavior, and diseases in the DT and NDT groups. Significant differences were observed between the two groups in annual family income among participants aged 30-39 years $(p=0.032)$. Significant differences were also observed between the two groups in night shift work among participants aged 30-39 years $(\mathrm{p}=0.001)$, and among all participants in aggregate $(\mathrm{p}<0.001)$.

Table 2 shows self-assessed oral health status in the DT and NDT groups. In the 30-39 age group, a higher percentage of participants with DT reported pain in the teeth or gingiva $(p=0.009)$, bad breath $(p=0.048)$, or frequent stomatitis $(p=0.035)$. In the 40-49 age group, a higher percentage of participants with DT reported pain when eating or drinking something cold $(p=0.002)$. This was also true for participants in both age groups combined $(p=0.041$ for pain when eating or drinking something cold; $\mathrm{p}<0.001$ for pain in the teeth or gingiva; and $\mathrm{p}=0.030$ for frequent stomatitis).

Table 3 shows the results for oral health behavior, again comparing the two groups. In the 40-49 age group, the percentage of participants with DT reporting eating between meals was higher $(p=0.047)$ and having a regular dental clinic lower $(p=0.013)$ than among those with NDT. Among all age groups combined, the percentage of participants with DT reporting eating between meals was 
Table 1 Comparison of basic characteristics, general health behavior, and diseases between DT and NDT by age group

\begin{tabular}{|c|c|c|c|c|c|c|c|c|c|c|}
\hline & & \multicolumn{3}{|c|}{ 30-39 years } & \multicolumn{3}{|c|}{$40-49$ years } & \multicolumn{3}{|c|}{ Total } \\
\hline & & $\%$ & $\mathrm{n}$ & & $\%$ & $\mathrm{n}$ & & $\%$ & $\mathrm{n}$ & \\
\hline & DT & 50.0 & 20 & & 50.0 & 20 & & 100.0 & 40 & \\
\hline & NDT & 50.0 & 51 & & 50.0 & 51 & & 100.0 & 102 & \\
\hline & & & & $\mathrm{p}$ value & & & $p$ value & & & $p$ value \\
\hline \multicolumn{11}{|c|}{ Annual family income } \\
\hline \multirow[t]{2}{*}{$<4$ million yen } & DT & 50.0 & 10 & \multirow{6}{*}{0.032} & 30.0 & 6 & & 40.0 & 16 & \multirow{6}{*}{0.059} \\
\hline & NDT & 23.5 & 12 & & 17.6 & 9 & & 20.6 & 21 & \\
\hline \multirow[t]{2}{*}{$4-6$} & DT & 35.0 & 7 & & 10.0 & 2 & 0146 & 22.5 & 9 & \\
\hline & NDT & 31.4 & 16 & & 31.4 & 16 & 0.180 & 31.4 & 32 & \\
\hline \multirow[t]{2}{*}{$\geq 6$} & DT & 15.0 & 3 & & 60.0 & 12 & & 37.5 & 15 & \\
\hline & NDT & 45.1 & 23 & & 51.0 & 26 & & 48.0 & 49 & \\
\hline \multicolumn{11}{|l|}{ Years of service } \\
\hline$<10$ years & DT & 85.0 & 17 & \multirow{4}{*}{0.092} & 55.0 & 11 & & 70.0 & 28 & \multirow{4}{*}{0.100} \\
\hline \multirow{3}{*}{$\geq 10$ years } & NDT & 64.7 & 33 & & 45.1 & 23 & 0.452 & 54.9 & 56 & \\
\hline & DT & 15.0 & 3 & & 45.0 & 9 & 0.452 & 30.0 & 12 & \\
\hline & NDT & 35.3 & 18 & & 54.9 & 28 & & 45.1 & 46 & \\
\hline \multirow[t]{2}{*}{ Night Shift } & DT & 50.0 & 10 & \multirow{2}{*}{0.001} & 30.0 & 6 & \multirow{2}{*}{0.173} & 40.0 & 16 & \multirow{2}{*}{$<0.001$} \\
\hline & NDT & 11.8 & 6 & & 15.7 & 8 & & 13.7 & 14 & \\
\hline \multirow[t]{2}{*}{ Current smoker } & DT & 50.0 & 10 & \multirow{2}{*}{0.143} & 30.0 & 6 & \multirow{2}{*}{0.787} & 40.0 & 16 & \multirow{2}{*}{0.389} \\
\hline & NDT & 31.4 & 16 & & 33.3 & 17 & & 32.4 & 33 & \\
\hline \multirow[t]{2}{*}{ Diabetes } & DT & 0.0 & 0 & \multirow{2}{*}{1.000} & 10.0 & 2 & \multirow{2}{*}{0.616} & 5.0 & 2 & \multirow{2}{*}{0.774} \\
\hline & NDT & 2.0 & 1 & & 5.9 & 3 & & 3.9 & 4 & \\
\hline \multirow[t]{2}{*}{ Hypertension } & $\mathrm{DT}$ & 15.0 & 3 & \multirow{2}{*}{0.132} & 10.0 & 2 & \multirow{2}{*}{0.714} & 12.5 & 5 & \multirow{2}{*}{0.638} \\
\hline & NDT & 3.9 & 2 & & 15.7 & 8 & & 9.8 & 10 & \\
\hline \multirow{2}{*}{$\begin{array}{l}\text { BMI } \\
25 \text { and over }\end{array}$} & DT & 45.0 & 9 & 0.359 & 35.0 & 7 & 0.769 & 40.0 & 16 & 0.389 \\
\hline & NDT & 33.3 & 17 & 0.000 & 31.4 & 16 & 0.70 & 32.4 & 33 & ..800 \\
\hline
\end{tabular}

DT: sales workers with untreated decayed teeth; NDT: sales workers with no untreated decayed teeth. Chi-squared test (or Fisher's exact test in cases with fewer than 5 cells in contingency table) was used to compare between two groups.

higher $(p=0.027)$ and visiting a dental clinic in the past 6 months lower $(p=0.017)$ than in those with NDT. In the 30-39 age group, participants with NDT were more likely to report an inability to visit a dental clinic when they wanted to $(p>0.05)$, whereas those with DT more often reported that the reason for being unable to visit a dental clinic was that multiple visits were required for treatment $(\mathrm{p}=0.016)$. In the 40-49 age group, participants with
NDT were again more likely to report an inability to visit a dental clinic when they wanted to $(p=0.005)$, whereas those with DT more often reported that the reason for being unable to visit a dental clinic was that they did not like treatment $(p=0.001)$. Among all age groups combined, participants with NDT were more likely to report an inability to visit a dental clinic when theywanted to $(p=0.033)$, whereas those with DT were more likely to 
Table 2 Comparison of oral health symptoms between DT and NDT by age group

\begin{tabular}{|c|c|c|c|c|c|c|c|c|c|c|}
\hline \multirow{4}{*}{ Mean number of teeth } & & \multicolumn{3}{|c|}{ 30-39 years } & \multicolumn{3}{|c|}{$40-49$ years } & \multicolumn{3}{|c|}{ Total } \\
\hline & \multirow{3}{*}{$\begin{array}{c}\text { DT } \\
\text { NDT }\end{array}$} & \multicolumn{3}{|r|}{$\mathrm{p}$ value } & \multicolumn{3}{|r|}{$p$ value } & \multicolumn{3}{|r|}{$\mathrm{p}$ value } \\
\hline & & \multirow{2}{*}{\multicolumn{2}{|c|}{$\begin{array}{l}25.3 \pm 5.9 \\
25.1 \pm 6.1\end{array}$}} & \multirow{2}{*}{0.931} & \multirow{2}{*}{\multicolumn{2}{|c|}{$\begin{array}{l}25.0 \pm 6.2 \\
27.1 \pm 5.1\end{array}$}} & \multirow{2}{*}{0.157} & $25.1=$ & & \multirow{2}{*}{0.356} \\
\hline & & & & & & & & $26.1=$ & 5.7 & \\
\hline Symptoms & & $\%$ & $\mathrm{n}$ & $\mathrm{p}$ value & $\%$ & $\mathrm{n}$ & $\mathrm{p}$ value & $\%$ & $\mathrm{n}$ & $p$ value \\
\hline \multirow{2}{*}{$\begin{array}{l}\text { Pain when eating/drink- } \\
\text { ing something cold }\end{array}$} & DT & 30.0 & 6 & \multirow{2}{*}{0.787} & 65.0 & 13 & \multirow{2}{*}{0.002} & 47.5 & 19 & \multirow{2}{*}{0.041} \\
\hline & NDT & 33.3 & 17 & & 25.5 & 13 & & 29.4 & 30 & \\
\hline \multirow{2}{*}{$\begin{array}{l}\text { Pain in the teeth or gin- } \\
\text { giva }\end{array}$} & DT & 35.0 & 7 & \multirow{2}{*}{0.009} & 25.0 & 5 & \multirow{2}{*}{0.105} & 30.0 & 12 & \multirow{2}{*}{$<0.001$} \\
\hline & NDT & 7.8 & 4 & & 7.8 & 4 & & 7.8 & 8 & \\
\hline \multirow[t]{2}{*}{ Gingival bleeding } & DT & 30.0 & 6 & \multirow{2}{*}{0.699} & 25.0 & 5 & \multirow{2}{*}{0.760} & 27.5 & 11 & \multirow{2}{*}{0.621} \\
\hline & NDT & 25.5 & 13 & & 21.6 & 11 & & 23.5 & 24 & \\
\hline \multirow[t]{2}{*}{ Gingival swelling } & DT & 20.0 & 4 & \multirow{2}{*}{0.092} & 20.0 & 4 & \multirow{2}{*}{0.491} & 20.0 & 8 & \multirow{2}{*}{0.100} \\
\hline & NDT & 5.9 & 3 & & 13.7 & 7 & & 9.8 & 10 & \\
\hline \multirow{2}{*}{$\begin{array}{l}\text { Difficulty opening the } \\
\text { mouth }\end{array}$} & DT & 10.0 & 2 & \multirow{2}{*}{0.189} & 10.0 & 2 & \multirow{2}{*}{0.314} & 10.0 & 4 & \multirow{2}{*}{0.098} \\
\hline & NDT & 2.0 & 1 & & 3.9 & 2 & & 2.9 & 3 & \\
\hline Bad breath & DT & 45.0 & 9 & 0048 & 20.0 & 4 & 0491 & 32.5 & 13 & 0054 \\
\hline & NDT & 21.6 & 11 & 0.070 & 13.7 & 7 & 0.91 & 17.6 & 18 & 0.057 \\
\hline Frequent stomatitis & DT & 25.0 & 5 & 0035 & 5.0 & 1 & 0487 & 15.0 & 6 & ( \\
\hline & NDT & 5.9 & 3 & 0.035 & 2.0 & 1 & 0.708 & 3.9 & 4 & 0.030 \\
\hline
\end{tabular}

DT: sales workers with untreated decayed teeth; NDT: sales workers with no untreated decayed teeth.

Chi-squared test (or Fisher's exact test in cases with fewer than 5 cells in contingency table) was used to compare between two groups.

Mann-Whitney $U$ test was used to compare number of teeth between two groups.

report that the reasons for being unable to visit a dental clinic were that multiple visits were required for treatment $(p=0.012)$ and that they did not like treatment $(p=0.005)$.

Table 4 shows which factors were revealed to contribute to the presence of DT by multiple logistic regression analysis. The independent variables found to be correlated with leaving decayed teeth untreated were night shift (OR, 3.492; 95\%CI, 1.347-8.725) and visiting a dental clinic in the past 6 months (OR, 0.084; 95\%CI, 0.010-0.733).

\section{Discussion}

Previous reports have indicated that a selfreported questionnaire is a feasible tool for measuring oral health conditions, such as number of present and decayed teeth ${ }^{2,27)}$. Oral health status is influenced by educational background, socioeconomic status, job stress, and $\operatorname{sex}^{4,6,17,23,25)}$. Therefore, to avoid interference from confounding factors as much as possible it is desirable to investigate participants with similar characteristics. With this in mind, male sales workers only were selected for inclusion in this study.

After adjusting for confounding factors, night shift work and not having visited a dental clinic in the past 6 months were determined to be risk factors for the presence of DT. The present finding that night shift work is a risk factor for the presence of DT supports that of an earlier study by Ishizuka et al. ${ }^{12}$. Furthermore, another earlier study found an association between shift work and periodontal health ${ }^{8)}$, where it was found that shift workers aged $\geq 45$ years were at higher risk for periodontitis. Unfavorable health conditions 
Table 3 Comparison of oral health behavior between DT and NDT by age group

\begin{tabular}{|c|c|c|c|c|c|c|c|c|c|c|}
\hline & & \multicolumn{3}{|c|}{ 30-39 years } & \multicolumn{3}{|c|}{ 40-49 years } & \multicolumn{3}{|c|}{ Total } \\
\hline & & $\%$ & $\mathrm{n}$ & $\mathrm{p}$ value & $\%$ & $\mathrm{n}$ & $\mathrm{p}$ value & $\%$ & $\mathrm{n}$ & $\mathrm{p}$ value \\
\hline \multicolumn{11}{|l|}{ Behavior } \\
\hline \multirow[t]{2}{*}{ Brushing teeth every day } & DT & 95.0 & 19 & \multirow{2}{*}{1.000} & 90.0 & 18 & \multirow{2}{*}{1.000} & 92.5 & 37 & \multirow{2}{*}{1.000} \\
\hline & NDT & 92.2 & 47 & & 92.2 & 47 & & 92.2 & 94 & \\
\hline \multirow{2}{*}{$\begin{array}{l}\text { Brushing twice or more } \\
\text { per day }\end{array}$} & DT & 65.0 & 13 & \multirow{2}{*}{0.423} & 68.4 & 13 & \multirow{2}{*}{0.860} & 66.7 & 26 & \multirow{2}{*}{0.491} \\
\hline & NDT & 74.5 & 38 & & 70.6 & 36 & & 72.5 & 74 & \\
\hline \multirow[t]{2}{*}{ Brushing before bed } & DT & 60.0 & 12 & \multirow{2}{*}{0.405} & 57.9 & 11 & \multirow{2}{*}{0.606} & 59.0 & 23 & \multirow{2}{*}{0.340} \\
\hline & NDT & 49.0 & 25 & & 51.0 & 26 & & 50.0 & 51 & \\
\hline \multirow[t]{2}{*}{ Using fluoride toothpaste } & DT & 55.0 & 11 & \multirow{2}{*}{0.129} & 40.0 & 8 & \multirow{2}{*}{0.951} & 47.5 & 19 & \multirow{2}{*}{0.263} \\
\hline & NDT & 35.3 & 18 & & 39.2 & 20 & & 37.3 & 38 & \\
\hline \multirow{2}{*}{$\begin{array}{l}\text { Spending } 3 \text { minutes or } \\
\text { more when brushing }\end{array}$} & DT & 40.0 & 8 & \multirow{2}{*}{0.810} & 42.1 & 8 & \multirow{2}{*}{0.420} & 41.0 & 16 & \multirow{2}{*}{0.455} \\
\hline & NDT & 43.1 & 22 & & 52.9 & 27 & & 48.0 & 49 & \\
\hline \multirow{2}{*}{$\begin{array}{l}\text { Using dental floss or an } \\
\text { interdental brush }\end{array}$} & DT & 50.0 & 10 & \multirow{2}{*}{0.408} & 40.0 & 8 & \multirow{2}{*}{0.493} & 45.0 & 18 & 0094 \\
\hline & NDT & 39.2 & 20 & & 49.0 & 25 & & 44.1 & 45 & 0.924 \\
\hline Eating between meals & DT & 75.0 & 15 & 0950 & 75.0 & 15 & 0047 & 75.0 & 30 & 0097 \\
\hline & NDT & 60.8 & 31 & 0.259 & 49.0 & 25 & 0.047 & 54.9 & 56 & $0.0<1$ \\
\hline Having a regular dental & DT & 65.0 & 13 & 0530 & 30.0 & 6 & 0013 & 47.5 & 19 & 0184 \\
\hline clinic & NDT & 56.9 & 29 & 0.500 & 62.7 & 32 & 0.013 & 59.8 & 61 & 0.184 \\
\hline Visited a dental clinic in & DT & 5.0 & 1 & 0969 & 0.0 & 0 & 0053 & 2.5 & 1 & 0017 \\
\hline the past 6 months & NDT & 17.6 & 9 & 0.203 & 17.6 & 9 & 0.053 & 17.6 & 18 & 0.017 \\
\hline Unable to visit a dental & DT & 40.0 & 8 & 0810 & 30.0 & 6 & 0005 & 35.0 & 14 & 0039 \\
\hline clinic when wanted to & NDT & 43.1 & 22 & 0.010 & 66.7 & 34 & 0.005 & 54.9 & 56 & 0.035 \\
\hline Reasons for being unable to & sit a de & tal clir & & & & & & & & \\
\hline Cannot go when clinic is & DT & 35.0 & 7 & 0629 & 30.0 & 6 & 0239 & 32.5 & 13 & 0710 \\
\hline & NDT & 41.2 & 21 & 0.032 & 17.6 & 9 & 0.535 & 29.4 & 30 & 0.119 \\
\hline Cannot afford treatment & DT & 0.0 & 0 & 0571 & 15.0 & 3 & 0199 & 7.5 & 3 & 0719 \\
\hline $\operatorname{cost}$ & NDT & 7.8 & 4 & 0.571 & 3.9 & 2 & 0.132 & 5.9 & 6 & 0.112 \\
\hline Too busy with work & DT & 35.0 & 7 & 0949 & 35.0 & 7 & 0128 & 35.0 & 14 & 0053 \\
\hline & NDT & 21.6 & 11 & 0.242 & 17.6 & 9 & 0.120 & 19.6 & 20 & \\
\hline Multiple visits required & DT & 25.0 & 5 & 0016 & 10.0 & 2 & 0314 & 17.5 & 7 & 0019 \\
\hline for treatment & NDT & 3.9 & 2 & 0.016 & 3.9 & 2 & 0.314 & 3.9 & 4 & 0.012 \\
\hline Dislike treatment & DT & 10.0 & 2 & 0616 & 25.0 & 5 & 0001 & 17.5 & 7 & 0005 \\
\hline & NDT & 5.9 & 3 & 0.010 & 0.0 & 0 & 0.001 & 2.9 & 3 & 0.005 \\
\hline
\end{tabular}

DT: sales workers with untreated decayed teeth; NDT: sales workers with no untreated decayed teeth.

Chi-squared test (or Fisher's exact test in cases with fewer than 5 cells in contingency table) was used to compare between two groups.

among night workers have been reported. With respect to lifestyle, night shift nurses had more unhealthy dietary behaviors than those without night shifts in a study of 340 hospital nurses $^{9}$. Moreover, shift work was associated with stress and behavioral changes and eventually caused disease ${ }^{13)}$. Taken together, these studies suggest that night shift work causes behavioral changes and has a negative effect on not only general health, but also oral 
Table 4 Factors contributing to leaving decayed teeth untreated by multiple logistic regression analysis $(\mathrm{n}=142)$

\begin{tabular}{lllll}
\hline \hline \multicolumn{1}{c}{ Independent variable } & & OR & 95\%CI & p value \\
\hline Age & $30-39$ years & 1 & & \\
& $40-49$ & 1.154 & $0.509-2.620$ & 0.731 \\
Annual household income & $<4$ million yen & 1 & & \\
& $4-6$ & 0.339 & $0.113-1.018$ & 0.054 \\
& $\geq 6$ & 0.448 & $0.164-1.226$ & 0.118 \\
Eating between meals & No & 1 & & \\
Night shift & Yes & 2.322 & $0.959-5.624$ & 0.062 \\
& No & 1 & & \\
Visited a dental clinic in the past 6 months & Yes & 3.492 & $1.347-8.725$ & 0.010 \\
& No & 1 & & \\
& Yes & 0.084 & $0.010-0.733$ & 0.025 \\
\hline
\end{tabular}

OR: odds ratio; CI: confidence interval.

health. Indeed, in the current study it is clear that despite a higher percentage of those in the DT group reporting pain when eating or drinking something cold and pain in the teeth or gingiva, they were still leaving their decayed teeth untreated, eating between meals, and fewer of them had visited a dental clinic in the past 6 months compared to in the NDT group.

Night work was found to disturb regular dental attendance, with the percentage of employees adhering to $<70 \%$ of appointments being higher among night workers $(23.5 \%)$ than among non-night workers $(7.5 \%)^{30)}$. Not visiting a dental clinic in the past 6 months was associated with having at least one untreated decayed tooth (OR, 0.084) in the present study. Previous reports have also shown a negative association between regular dental visits and decayed teeth $^{6,23)}$. Irregular dental visitation was associated with at least one decayed surface (OR, $2.03)^{6}$. This indicates that regularly visiting a dentist decreases the likelihood of DT.

Low socioeconomic status was identified as a barrier to dental attendance, and such barriers appear to have negative effects on oral health $^{5,15}$. Universal health insurance in Japan covers most illnesses, so anyone can receive care at any hospital in the country. Therefore,
Japanese people can access treatment more easily and at a lower cost than in most areas of the world ${ }^{26)}$. However, it was not possible to obtain detailed information regarding socioeconomic status in the present study. Therefore, there is a need for future inquiry into how this factor influences sales workers' behavior.

In this study, participants in the DT group were more likely to be night shift workers and eat between meals than those in the NDT group. Despite a higher percentage of participants in the DT group reporting pain when eating or drinking something cold and pain in the teeth or gingiva, more of those in the DT group were leaving decayed teeth untreated, and fewer of them had visited a dental clinic in the past 6 months compared to in the NDT group. Those in the DT group were less likely to report an inability to visit a dental clinic when they wanted to, and they reported that the reasons for being unable to visit a dental clinic were that multiple visits were required for treatment and that they disliked treatment, not because they could not go when the clinic was open or because they were too busy with work. Dental anxiety is a major impediment to dental attendance, contributing to irregular dental attendance patterns $^{28}$. The dental profession should con- 
sider these factors when planning programs to enhance access to dental care service.

This study had several limitations, the first of which is the possibility of selection bias due to the data being obtained by means of an Internet survey. The second limitation is that the oral health status information was selfassessed and self-reported. The third limitation is that data regarding the night shift workers' schedules, such as those concerning overtime, use of flextime, break time, and number of holidays, were not taken into consideration. The final limitation of this study is that it was based on a cross-sectional survey.

Despite these limitations, however, the present results revealed that night shift work and not visiting a dental clinic in the past 6 months were associated with leaving decayed teeth untreated among male sales workers. These findings suggest that requiring oral health education and dental checkups at least once every 6 months may have a positive effect on oral health among male sales workers, especially those undertaking night shifts.

\section{Acknowledgements}

This study was supported by the 'Research Fund of Clinical Study for Industrial Accident and Diseases' (14020101-02) from the Japanese Ministry of Health, Labour and Welfare.

\section{References}

1) Aida J, Ando Y, Akhter R, Aoyama H, Masui M, Morita M (2006) Reasons for permanent tooth extractions in Japan. J Epidemiol 16: 214-219.

2) Axelsson G, Helgadottir S (1995) Comparison of oral health data from self-administered questionnaire and clinical examination. Community Dent Oral Epidemiol 23:365368.

3) Cherry N, Meyer JD, Adisesh A, Brooke R, Owen-Smith V, Swales C, Beck MH (2000) Surveillance of occupational skin disease: EPIDERM and OPRA. Br J Dermatol 142:
1128-1134.

4) Costa SM, Martins CC, Bonfim Mde L, Zina LG, Paiva SM, Pordeus IA, Abreu MH (2012) A systematic review of socioeconomic indicators and dental caries in adults. Int J Environ Res Public Health 9:3540-3574.

5) Donaldson AN, Everitt B, Newton T, Steele J, Sherriff M, Bower E (2008) The effects of social class and dental attendance on oral health. J Dent Res 87:60-64.

6) Edman K, Ohrn K, Nordstrom B, Holmlund A (2016) Prevalence of dental caries and influencing factors, time trends over a 30-year period in an adult population. Epidemiological studies between 1983 and 2013 in the county of Dalarna, Sweden. Acta Odontol Scand 74:385-392.

7) el Batawi MA (1984) Work-related diseases. A new program of the World Health Organization. Scand J Work Environ Health 10:341-346.

8) Han DH, Khang YH, Jung-Choi K, Lim S (2013) Association between shift work and periodontal health in a representative sample of an Asian population. Scand J Work Environ Health 39:559-567.

9) Han K, Choi-Kwon S, Kim KS (2016) Poor dietary behaviors among hospital nurses in Seoul, South Korea. Appl Nurs Res 30:38-44.

10) Harada Y, Takeuchi K, Furuta M, Tanaka A, Tanaka S, Wada N, Yamashita Y (2018) Genderdependent associations between occupational status and untreated caries in Japanese adults. Ind Health 56:539-544.

11) Irie $K$, Yamazaki $T$, Yoshii $S$, Takeyama $H$, Shimazaki Y (2017) Is there an occupational status gradient in the development of periodontal disease in Japanese workers? A 5-year prospective cohort study. J Epidemiol 27: 69-74.

12) Ishizuka $Y$, Yoshino K, Takayanagi A, Sugihara N, Maki Y, Kamijyo H (2016) Comparison of the oral health problems and behavior of male daytime-only and night-shift office workers: An Internet survey. J Occup Health 58:155162.

13) Knutsson A (2003) Health disorders of shift workers. Occup Med (Lond) 53:103-108.

14) Langard S, Lee LJ (2011) Methods to recognize work-related cancer in workplaces, the general population, and by experts in the clinic, a Norwegian experience. J Occup Med Toxicol 6:24.

15) Locker D, Maggirias J, Quinonez C (2011) Income, dental insurance coverage, and financial barriers to dental care among Canadian adults. J Public Health Dent 71:327-334.

16) Marcinkiewicz A, Szosland D (2010) Selected 
risk factors of diabetes mellitus among road transport drivers. Int J Occup Med Environ Health 23:175-180.

17) Mejia-Rubalcava C, Alanis-Tavira J, ArguetaFigueroa L, Legorreta-Reyna A (2012) Academic stress as a risk factor for dental caries. Int Dent J 62:127-131.

18) Miyamoto M, Konno S, Gembun Y, Liu X, Minami K, Ito H (2008) Epidemiological study of low back pain and occupational risk factors among taxi drivers. Ind Health 46:112-117.

19) Montano D (2014) Chemical and biological work-related risks across occupations in Europe: a review. J Occup Med Toxicol 9:28.

20) Morita I, Nakagaki H, Yoshii S, Tsuboi S, Hayashizaki J, Igo J, Mizuno K, Sheiham A (2007) Gradients in periodontal status in Japanese employed males. J Clin Periodontol 34:952-956.

21) Morita I, Nakagaki H, Yoshii S, Tsuboi S, Hayashizaki J, Mizuno K, Sheiham A (2007) Is there a gradient by job classification in dental status in Japanese men? Eur J Oral Sci 115: 275-279.

22) Morita M, Kimura T, Kanegae M, Ishikawa A, Watanabe T (1994) Reasons for extraction of permanent teeth in Japan. Community Dent Oral Epidemiol 22:303-306.

23) Petersen PE (2005) Sociobehavioural risk factors in dental caries-international perspectives. Community Dent Oral Epidemiol 33: 274-279.

24) Punnett L, Wegman DH (2004) Work-related musculoskeletal disorders: the epidemiologic evidence and the debate. J Electromyogr Kinesiol 14:13-23.

25) Schwendicke F, Dorfer CE, Schlattmann P, Foster Page L, Thomson WM, Paris S (2015) Socioeconomic inequality and caries: a systematic review and meta-analysis. J Dent Res 94: 10-18.

26) Shibuya K, Hashimoto H, Ikegami N, Nishi A, Tanimoto T, Miyata H, Takemi K, Reich MR (2011) Future of Japan's system of good health at low cost with equity: beyond universal coverage. Lancet 378:1265-1273.

27) Silva AE, Menezes AM, Assuncao MC, Goncalves H, Demarco FF, Vargas-Ferreira F,
Peres MA (2014) Validation of self-reported information on dental caries in a birth cohort at 18 years of age. PLoS One 9: e106382.

28) Sohn W, Ismail AI (2005) Regular dental visits and dental anxiety in an adult dentate population. J Am Dent Assoc 136:58-66; quiz 90-51.

29) Stansfeld S, Candy B (2006) Psychosocial work environment and mental health-a meta-analytic review. Scand J Work Environ Health 32: 443-462.

30) Suzuki S, Sugiyama S, Okamoto M, Tanaka M, Takayanagi A, Yoshino K, Ishizuka Y, Satou R, Kamijo H, Sugihara N (2016) Working environment factors associated with regular dental attendance. Bull Tokyo Dent Coll 58: 193-197.

31) Suzuki S, Yoshino K, Takayanagi A, Ishizuka Y, Satou R, Kamijo H, Sugihara N (2016) Comparison of risk factors for tooth loss between professional drivers and white-collar workers: an internet survey. Ind Health 54: 246-253.

32) Swerdlow AJ, Skeet RG (1988) Occupational associations of testicular cancer in south east England. Br J Ind Med 45:225-230.

33) Yoshida K (2017) Clinical and phenomenological characteristics of patients with taskspecific lingual dystonia: Possible association with occupation. Front Neurol 8:649.

34) Yoshino K, Ito K, Kuroda M, Sugihara N (2015) Prevalence of vertical root fracture as the reason for tooth extraction in dental clinics. Clin Oral Investig 19:1405-1409.

35) Zaitsu T, Kanazawa T, Shizuma Y, Oshiro A, Takehara S, Ueno M, Kawaguchi Y (2017) Relationships between occupational and behavioral parameters and oral health status. Ind Health 55:381-390.

\section{Correspondence:}

Dr. Yoichi Ishizuka

Department of Epidemiology and Public Health,

Tokyo Dental College, 2-9-18 Kanda-Misakicho, Chiyoda-ku, Tokyo 101-0061, Japan

E-mail: ishizukayouichi@tdc.ac.jp 